\title{
Walk this way: improving activity levels
}

\author{
Emeritus Professor Alan Glasper, from the University of Southampton, discusses ways of increasing daily \\ exercise, especially walking, as a way of tackling obesity and its effects on health
}

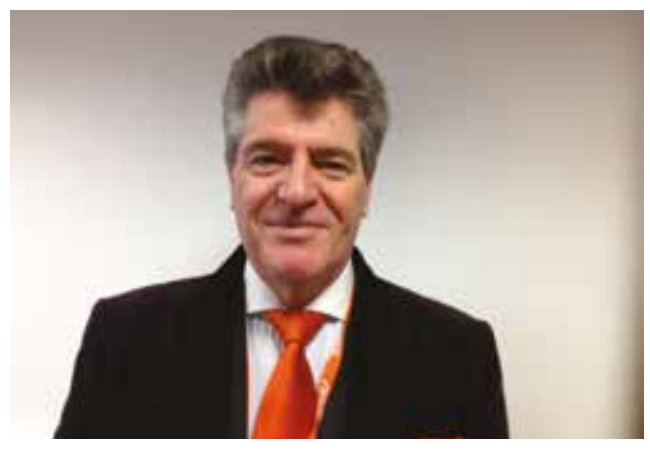

A

nyone who has visited their GP recently cannot have failed to notice the prominently displayed posters extolling the mantra that walking can be seriously good for your health.

The health benefits of walking have been subject to stringent research, with Marigliano et al (2016), for example, showing that moderately intensive walking can improve cardiovascular risk factors. The World Health Organization (WHO) recommends that all adults undertake 150 minutes of moderate exercise a week and, for additional health benefits, adults should increase their moderate-intensity aerobic physical activity to 300 minutes each week (WHO, 2017).

In a systematic review of the literature, Hupin et al (2015) have shown that even moderate activities such as regular walking can reduce mortality by $22 \%$ in older adults. Not only does regular exercise reduce the risk of premature death, but this health benefit exists even if people do less than the recommended 150 minutes. The National Institute for Health and Care Excellence (NICE) recognised that exercise is beneficial for managing the weight and improving the lifestyle of overweight and obese adults (NICE, 2014a).

NICE acknowledges that walking and other forms of physical exercise are best undertaken in natural environments. It has called on the designers and managers of public open spaces, paths and rights of way (including coastal, forest and riverside paths and canal towpaths), as well as planning and transport agencies, to ensure that such areas can be reached easily. Open spaces should be accessible on foot, by bicycle and by public transport. Such areas should be maintained to a high standard and be safe, attractive and welcoming to everyone (NICE, 2008).

\section{Background}

The direct cost of physical inactivity to the NHS across the UK has been estimated at ¿1.06 billion (Royal College of Physicians (RCP) et al, 2016). This is based on the cost of treating medical conditions such as heart disease and diabetes, which are inextricably linked to inactivity. It is estimated that increased walking and cycling in urban England and Wales could save the NHS \&17 billion over the next 20 years (RCP et al, 2016).

Nurses and other health professionals are not immune to the obesity pandemic that has plagued the western world. In 2009 a cross-government strategy to address obesity in England estimated that of the 1.2 million staff in the NHS, around 300000 would be classified as obese and a further 400000 as overweight (Public Health England, 2009).

Research on obesity conducted among large cohorts of nurses in Australia, New Zealand and the UK showed that $61.87 \%$ fell outside the healthy weight range. Being overweight or obese was linked with increasing age among this population (Bogossian et al, 2012). This research showed that nurses were more likely to be overweight than the general population of the country in which they lived. The researchers suggest that being overweight could adversely impact on nurses' ability to optimally contribute to the functioning of the nursing team.

The high levels of obesity within the NHS workforce was recognised by the RCP in 2015 when it published guidance on weight management for health service employees (RCP, 2015).

Such high levels of obesity among healthcare staff has not escaped the attention of the media, with one article suggesting that it might seem hypocritical for health workers to give health advice to patients when they are overweight themselves (Hammond, 2014).

Alterman et al (2013) suggested that workrelated factors may contribute to the high prevalence of obesity in the US health service. They believe that the way to tackle obesity among health workers is for employers to consider workplace interventions that target organisation-level factors, such as shift scheduling and the prevention of workplace bullying, along with individual-level factors, such as diet and exercise. However, the advice on weight management through exercise sometimes fails to take into account the difficulty of exercising when working the 12-hour shifts that are now so ubiquitous.

\section{Weight management for health service employees}

The RCP provides guidance on weight management for health service employees (RCP, 2015). It recommends that employers should implement NICE guidelines on obesity (NICE, 2006; NICE, 2014b) by:

- Ensuring healthy food is available in the workplace at affordable or subsidised prices

- Encouraging nutritional labelling to allow employees to make informed food choices

- Setting strict nutritional criteria as part of procurement contracts for food outlets and vending machines (RCP, 2015).

Employers should encourage physical activity by:

- Advising staff to walk and use stairs rather than lifts

- Recommending the use of active travel methods to and from work, such as walking and cycling, and providing changing facilities and cycle-storage areas 
- Working with local authorities to enhance access to health services by public transport

- Considering the use of staff incentives such as discounted membership of fitness clubs (RCP, 2015).

Employers should encourage healthy

behaviour change by:

- Developing a strategy for staff health and wellbeing

- Encouraging staff to take regular breaks to move around as well as sufficient time to eat well

- Using innovative ways to encourage lifestyle change among staff, such as intranet messages on health, and signposting local activity/weight management opportunities

- Communicating the health benefits of weight loss, and publicising in-house or community-based weight-loss services (RCP, 2015).

\section{Health benefits of walking}

The RCP advises nurses and others to walk more, but how much is 'more' (RCP, 2015)?

Healthy adults should aspire to achieve a target of 10000 steps a day (NHS Choices, 2014). An average person has a stride length of approximately 2.1 to 2.5 feet, which equates to 2000 steps to the mile, with 10000 steps equalling 5 miles. Walking is often overlooked as a form of exercise but is recommended, especially because it can be undertaken almost anywhere, at any time and in any weather.

Pedometers can be used to ascertain how many steps have been taken each day (NHS Choices, 2014). Increasingly, people are also using fitness tracker apps on their mobile phones to monitor their activity. Walking 10000 steps, which equates to about 2 hours of walking, will result in the burning of approximately 400 calories or up to 2800 calories per week. This represents a weight loss of about a pound in weight over the week or half a stone over a calendar month.

Many nurses would find it impossible to take 2 hours out of their day to walk. But increasing walking time is easier than most people think. Two hours represents about $16 \%$ of a 12 -hour shift and the solution is

J for nurses to find ways of taking 10000 steps during their working day (NHS Choices, 2014). This can be achieved by:

- Getting off public transport earlier than usual and walking the rest of the way home or to work, or walking to the station instead of taking the car or bus

- Taking the stairs instead of the lift at work

- When not at work, investing in a shopping trolley and shopping locally where possible and walking the children to school

- Buying a pair of lightweight walking shoes and getting fit through walking in open spaces and perhaps joining a walking group.

\section{Therapeutic benefits}

There is no doubt that many nurses are prone to stress while working, and mindfulness meditation has been shown to manage this effectively (Galantino et al, 2005).

National parks such as the New Forest offer many opportunities for outdoor activities. A report on practising mindfulness in woods and forests discusses the holistic benefits of walking in rural and wooded environments (Ambrose-Oji, 2013).

'Forest bathing', the Japanese philosophy of shinrin-yoku, is a term that means 'taking in the forest atmosphere' and it is an important aspect of preventive health in Japanese medicine (Tsunetsugu et al, 2010). Japanese citizens are encouraged to use forests as therapeutic environments in which to manage stress. Forests are also home for many species of birds and research has indicated that there is a link between such environments and better mental health (Cox et al, 2017).

Health workers who live in urban areas can access the many parks and open green spaces found in most towns and cities.

\section{Conclusion}

Walking is becoming an increasingly popular intervention for getting fitter and losing weight, as well as helping with stress. Obesity and stress among health professionals can be mitigated through mindful walking, especially in natural environments. BJN

Alterman T, Luckhaupt SE, Dahlhamer JM, Ward BW, Calvert GM (2013) Prevalence rates of work organization characteristics among workers in the US: data from the 2010 National Health Interview Survey. Am J Ind Med 56(6): 647-59. https://dx.doi. org/10.1002/ajim.22108

Ambrose-Oji B (2013) Mindfulness Practice in Woods and Forests: An Evidence Review. Research Report for the Mersey Forest. Forest Research, Farnham

Bogossian FE, Hepworth J, Leong GM et al (2012) A cross-sectional analysis of patterns of obesity in a cohort of working nurses and midwives in Australia, New Zealand, and the United Kingdom. Int J Nurs Stud 49(6): 727-38. https://dx.doi.org/10.1016/j. ijnurstu.2012.01.003

Cox DTC, Shanahan DF, Hudson HL et al (2017) Doses of neighborhood nature: the benefits for mental health of living with nature. BioScience 67(2): 147-55. https:// dx.doi.org/10.1093/biosci/biw173

Galantino ML, Baime M, Maguire M, Szapary PO, Farrar J

\section{KEY POINTS}

- The health benefits of walking have been subject to stringent research and moderately intensive walking can improve health and prevent weight gain

- Of the 1.2 million staff in the NHS, around 300000 would be classified as obese and a further 400000 as overweight

- Nurses and other health workers should aspire to walk 10000 steps per day

- Mindful walking and 'forest bathing' have been shown to be a therapeutic way of managing weight

(2005) Association of psychological and physiological measures of stress in health-care professionals during an 8-week mindfulness meditation program: mindfulness in practice. Stress and Health 21(4): 255-61. https:// dx.doi.org/10.1002/smi.1062

Hammond P (2014) Why are so many NHS workers obese? Daily Telegraph 13 November. http://bit. ly/2m6nPGd (accessed 9 March 2017)

Hupin D, Roche F, Gremeaux V et al (2015) Even a lowdose of moderate-to-vigorous physical activity reduces mortality by $22 \%$ in adults aged $\geq 60$ years: a systematic review and meta-analysis. Br J Sports Med 49(19): 12627. https://dx.doi.org/10.1136/bjsports-2014-094306

Marigliano E, Fahs PS, Ludden C (2016) Walking for heart health: a study of adult women in rural New York. Creative Nursing 22(4): 268-75

National Institute for Health and Care Excellence (2006) Obesity: guidance on the prevention, identification, assessment and management of overweight and obesity in adults and children. Clinical guideline 43. http://bit. ly/2mKa0kg (accessed 9 March 2017)

National Institute for Health and Care Excellence (2008) Physical activity and the environment. Public health guideline 8. http://bit.ly/2nabXEb (accessed 9 March 2017)

National Institute for Health and Care Excellence (2014a) Weight management: lifestyle services for overweight or obese adults. Public health guideline 53. http://bit. ly/2na3FvO (accessed 9 March 2017)

National Institute for Health and Care Excellence (2014b) Obesity: identification, assessment and management. Clinical guideline 189. http://bit.ly/2mF0qij (accessed 9 March 2017)

NHS Choices (2014) The 10000 steps challenge. http://bit. ly/P4EF6J (accessed 9 March 2017)

Public Health England (2009) Healthy Weight, Healthy Lives: One Year On. http://bit.ly/2mKjpbE (accessed 9 March 2017)

Royal College of Physicians (2015) Action on Obesity: Comprehensive Care for All. http://bit.ly/2mp5eIe (accessed 9 March 2017)

Royal College of Physicians, Faculty of Public Health and Royal College of Paediatrics and Child Health (2016) Department for Transport: Cycling and Walking Investment Strategy: Royal College of Physicians, Faculty of Public Health and Royal College of Paediatrics and Child Health Joint Submission. http://bit.ly/2mprKkd (accessed 9 March 2017)

Tsunetsugu Y, Park BJ, MiyazakiY (2010) Trends in research related to 'Shinrin-yoku' (taking in the forest atmosphere or forest bathing) in Japan. Environ Health Prev Med 15(1): 27-37. https://dx.doi.org/10.1007/ s12199-009-0091-z

World Health Organization (2017) Physical activity and adults. http://bit.ly/1soQ18O (accessed 9 March 2017) 